



\section{Contextualización teórica de los mecanismos de protección en el mundo de la moda colombiana}

\author{
Theoretical contextualization of the protec- \\ tion mechanisms in the Colombian fashion \\ world
}

\author{
Paola Andrea Zuluaga Ortiz (Colombia) \\ Institución Universitaria Politécnico Grancolombiano \\ paolazuluagaortiz@gmail.com \\ Abogada especialista en Derecho Comercial de la Universidad \\ del Rosario. Pertenece al grupo de investigación Derecho, \\ Justicia y Globalización del Programa de Derecho del Politécnico \\ Grancolombiano.
}

\author{
Contextualizacão teórica dos mecanismos \\ de proteção no mundo da moda colombiana
}

\section{Resumen}

Este artículo es el resultado de la primera parte de la investigación titulada "Mecanismos de protección en el mundo de la moda colombiana". El documento presenta la importancia actual económica y social de la moda en Colombia, así como las dos posturas existentes frente a la protección de las creaciones de moda, mediante una norma redactada exclusivamente para estos casos. Así mismo, hace una breve explicación de cómo podrían protegerse estas creaciones con la normativa vigente de derechos de autor y propiedad industrial. Para lograr su objetivo, en la primera parte presenta una breve contextualización del mercado de la moda en Colombia; posteriormente hace una referencia de los diferentes argumentos presentados por quienes abogan por una normativa especial que regule estas creaciones, y por quienes rechazan esta postura, y creen en la libre circulación; en la tercera parte realiza una presentación de los posibles mecanismos legislativos vigentes que podrían tutelar este tipo de creaciones; y finalmente concluye que por medio de la normativa de derechos de autor y de propiedad industrial es posible proteger estas creaciones.

\section{Abstract}

This article is the result of the first part of a research project entitled "Mechanisms of protection in the Colombian fashion world." The document presents the current economic and social importance of fashion in Colombia, and the two positions about the protection of fashion creations by specific law. Also, a brief explanation of how they could protect these creations with the legislation of copyright and industrial property. In the first part presents a brief contextualization of the fashion market in Colombia; then a reference to the various arguments advanced

\section{Resumo}

Este artigo é o resultado da primeira parte da pesquisa titulada "Mecanismos de proteção no mundo da moda colombiana". O documento apresenta a importância atual econômica e social da moda na Colômbia, assim como as duas posturas existentes frente à proteção das criações de moda, mediante uma norma redigida exclusivamente para estes casos. Assim mesmo, faz uma breve explicação de como poderiam proteger-se estas criações com a normativa vigente de direitos de autor e propriedade industrial. Para atingir o seu objetivo, na primeira parte 
by advocates of special regulations governing these creations, and those who reject this position, and believe in free circulation; the third part makes a presentation of the possible mechanisms that could protect existing legislative these creations; and finally concludes that by the rules of copyright and industrial property is possible to protect these creations.

Palabras clave: Moda, protección, derechos de autor, propiedad intelectual, propiedad industrial, piratería apresenta uma breve contextualização do mercado da moda na Colômbia; posteriormente faz uma referência dos diferentes argumentos apresentados por quem abocam por uma normativa especial que regule estas criações, e por quem rejeitam esta postura, e creem na livre circulação; na terceira parte realiza uma apresentação dos possíveis mecanismos legislativos vigentes que poderiam tutelar este tipo de criações; e finalmente conclui que por meio da normativa de direitos de autor e de propriedade industrial é possível proteger estas criações.

Key words: Fashion, protection, copyright, intellectual property, industrial property, piracy

Palavras chave: Moda, proteção, direitos de autor, propriedade intelectual, propriedade industrial, pirataria.

\section{Para citar este artículo / To cite this article / Para citar este artigo}

Zuluaga, Paola (2012). Contextualización teórica de los mecanismos de protección en el mundo de la moda colombiana . Panorama, VII (12), $97-121$. 


\section{Introducción}

Actualmente las personas se preocupan cada vez más por su apariencia y por las prendas de vestir, "lo que nos lleva a pensar, que el siglo XXI es desde ya mismo ultrafashion. ¿Exagerado? ¿Hemos borrado demasiado a la ligera las estrategias económicas, las cuestiones geopolíticas, los equilibrios ecológicos, las tensiones, las injusticias, los peligros que acechan al clima del mundo? Sí, es cierto” (Lannelongue, 2008, p.12).

Bañuelos (2011, p.2) sostiene que la moda se considera una de las estructuras más comunes y cotidianas de aculturación, igualmente, constituye un cambio temporal de estilo, es decir, de los componentes estéticos de la vida. Cuando se habla de moda, se debe entender está en un contexto global en el que están incluidas las prendas de vestir, la arquitectura, el diseño de interiores y exteriores, entre otros.

Según el Diccionario de la Real Academia de la Lengua Española en su vigésima tercera edición, moda es uso, modo o costumbre que está en boga durante algún tiempo, o en determinado país, con especialidad en los trajes, telas y adornos, principalmente los recién introducidos.

Tal como lo consagra el Diccionario de la Real Academia de la Lengua Española, el término moda ha sido asociado desde tiempos remotos a la forma de vestir de las personas, a la parte estética que presenta cada individuo en el momento en que toma la decisión de escoger sus prendas de vestir y usarlas; ello, debido a la identificación que existe entre moda y moda de vestir.

La moda es una disciplina que existe desde tiempos inmemoriales. Es una de esas cosas que parece haber estado siempre presente en las sociedades civilizadas (Anónimo, 2011, p.1), por lo que es impensable haber podido vivir sin usar prendas de vestir. Es por esto, que la moda se considera el espejo en el que se miran las sociedades donde existe; es a la vez un fenómeno cultural y un negocio altamente complejo y, como tal, reflejo de las actitudes sociales, económicas, sexuales y políticas de una época, tal como lo afirma Mackenzie (2010, p.6).

La mayoría de expertos, entre ellos Tungate (2008, p.19), concuerdan en señalar que la moda, tal y como la conocemos en la actualidad, nació en la capital francesa. Remaury, citado por Tungate (2008, p.19), señala que el término fashion, propiamente dicho, proviene del francés facón, que significa trabajar de una determinada manera, y travaux à facón es el término francés que tradicionalmente se designaba a la modistería.

Después de varios movimientos de las artes decorativas tales como: el barroco, rococó, exotismo, naturalismo, neoclasicismo, dandismo, romanticismo, industrialismo y savile row, surge en el siglo XIX la alta costura. Mackenzie (2010, p44) sostiene que la alta costura consolidó el papel del diseñador como árbitro de tendencias y elevó el oficio de la confección a la categoría de arte. 
Posteriormente, se presentaron otros movimientos entre ellos: ritualismo, bloomerismo, prerrafaelismo, esteticismo, racionalismo, belle époque, neoimperio, orientalismo; y fue allí, tal como lo indica Vásquez (2007, p.4), después de la Primera Guerra Mundial, que surge el prêt à porter, también llamada moda industrial.

El cambio de la alta costura al prêt à porter genero una democratización de la moda. Mientras que el consumo de la alta costura se limitaba a las clases sociales más ricas, la moda industrial generó acceso a las clases medias. A partir de ese momento surgieron otros movimientos conocidos como modernidad, moda de Hollywood, surrealismo, neovictoriano, utilitario, new look, neoeduardiano, existencialismo, boutique británico, espacial, glam, romanticismo nostálgico, casualismo, vanguardismo japonés, yuppismo, grunge, deconstruccionismo, posmodernismo, minimalismo, celebrities, marcas, vintage y globalism, los cuales forjaron el acceso de las clases bajas al mundo de la moda.

Hoy día, todos los integrantes de la sociedad tienen acceso a la moda. Algunos autores sostienen que la democratización significó una reducción de los signos de diferenciación social. Para tales autores, la moda, no ha eliminado los signos de rango social, sino que los ha reemplazado promoviendo referencias que valoran más otros atributos como la esbeltez, juventud, etc. (Vásquez, 2007, p.5).

Debido al acceso masivo de compradores de moda, actualmente, el mundo de la moda es una industria de miles de millones de dólares que no tiene fronteras nacionales. Revistas y periódicos incluyen la industria como parte de su cobertura en noticias, centrándose en el siempre cambiante mundo de las expresiones de diseño (Mencken, 1997).

\section{Contextualización teórica: mercado de moda en Colombia}

Colombia es reconocida por sus pasarelas en Latinoamérica, entre ellas, las más importantes Colombiamoda y Colombiatex, que atraen reconocidas empresas a nivel internacional. La industria ha crecido en 11,8\% en los últimos años, participa con un $0,31 \%$ y $0,17 \%$ en el valor total mundial en la producción de textiles y confecciones respectivamente, y con un $0,25 \%$ en el mercado de las pasarelas. En nuestro país la producción del sector de la moda representa el 11\% de la producción manufacturera, el 1,7\% del Producto Interno Bruto y genera más de 800 mil empleos (Proexport, 2009).

Durante la edición número 22 de Colombiamoda, la feria más importante de moda del país, celebrada entre el 26 y 28 de Julio de 2011, asistieron 9.428 personas, lo que significó un incremento del 6\%, frente a 2010. La participación de compradores internacionales llegó a 1.415 personas, provenientes de 51 países, frente a 30 países en 2010 (Alcaldía de Medellín, 2011).

Por su parte, la presencia de compradores nacionales aumentó en un 8\%, con 8.013 registrado. El pabellón nuevos modelos de negocios contó con 28 empresas y más de 60 inversionistas nacionales e internacionales. Adicionalmente, se estima la apertura de 90 nuevas tiendas para las marcas presentes en el transcurso de un año, las cuales podrían generar ventas por US\$18 millones en ese mismo período. Por otro lado, se realizó el Segundo 
Encuentro Nacional Empresarial y también trajo una delegación de 10 compradores internacionales; estas actividades generaron expectativas de negocios por US\$1.8 millones (Inexmoda, 2010).

En el mundo de la moda Colombiana interactúan grandes empresas nacionales como Fabricato Tejicondor, Vestimundo con dos marcas propias de moda GEF y Baby Fresh, Leonisa y C.I. El Globo (Anónimo, 2011, p.24); y también marcas como Arturo Calle, Armi, Pronto, Tennis, Punto Blanco, Hot Line entre otras; diseñadores de alto reconocimiento como Silvia Tscherassi, Pepa Pombo, Amelia Toro, Ángel Yañez, María Luisa Ortíz, Juan Pablo Martínez, Lina Cantillo, Julieta Suárez, Isabel Henao, Olga Piedrahita y pequeñas industrias, marcas y diseñadores que no tienen mayor recordación.

Independientemente del reconocimiento de los actores dentro del negocio, la Industria de la moda en Colombia ha tenido un desarrollo importante en los últimos años, por este motivo, \y teniendo en cuenta las expectativas que se han generado con la posible suscripción de tratados de libre comercio con otros países $\square$ es muy probable que esta industria siga creciendo, por lo que es importante determinar cómo podrían protegerse las creaciones que se generen en el interior de ella.

\section{Legislación vigente}

Colombia en su afán de proteger las obras y/o creaciones intelectuales ha suscrito varios convenios, tratados, leyes comunitarias, e internas, que buscan tutelar los derechos conferidos a este tipo de propiedad; no obstante, frente al tema de moda ha surgido una disputa.

Dentro del debate que surge a partir de la protección de las creaciones generadas en el mundo de la moda de vestuario, algunos tratadistas consideran importante e indispensable generar mecanismos de protección dentro de las leyes de propiedad intelectual; otros por el contrario, consideran que no es necesario y por tanto, no están de acuerdo con proteger las creaciones que se desarrollan dentro de este negocio.

El término propiedad intelectual tal como lo indica la Organización Mundial de la Propiedad Intelectual, se refiere a las creaciones de la mente: invenciones, obras literarias y artísticas, así como símbolos, nombres e imágenes utilizadas en el comercio. La propiedad intelectual se divide en dos categorías: propiedad industrial y derechos de autor (Organización Mundial de la Propiedad Intelectual 2011, p.2).

La propiedad industrial incluye las patentes, modelos de utilidad, diseños industriales, las marcas, las denominaciones de origen, y los secretos industriales; mientras que los derechos de autor están compuestos por obras literarias, tales como novelas, poemas y obras de teatro, películas, obras musicales, obras artísticas, tales como dibujos, pinturas, fotografías y esculturas, y diseños arquitectónicos; así como los derechos conexos. 
Los derechos que surgen a partir de este tipo de propiedad, son similares a los que surgen con otros derechos de propiedad, es decir, permiten al creador o al titular beneficiarse de la protección de los intereses morales y patrimoniales, derivados de su autoría (Organización Mundial de la Propiedad Intelectual, 2011).

A partir de ello, la propiedad intelectual sería una herramienta para proteger las ideas y los trabajos generados por un diseñador en la industria de la moda (Australian Fashion Council, 2010, p.3). Sin embargo, no es claro el panorama, al leer en el Convenio de Berna para la Protección de las Obras Literarias y Artísticas de 1886, adherido por la ley nacional 33 de 1987, y el Convenio de París para la Protección de la Propiedad Industrial de 1883 adherido por la Ley nacional 178 de 1994, no se esclarece el tema de creación de moda y su protección.

Mientras que la Convención de Berna en su artículo segundo consagra que

"obras literarias y artísticas comprenden todas las producciones en el campo literario, científico y artístico, cualquiera que sea el modo o forma de expresión, tales como los libros, folletos y otros escritos; las conferencias, alocuciones, sermones y otras obras de la misma naturaleza; las obras dramáticas o dramático-musicales; las obras coreográficas y las pantomimas; las composiciones musicales con o sin letra; las obras cinematográficas, a las cuales se asimilan las obras expresadas por procedimiento análogo a la cinematografía; las obras de dibujo, pintura, arquitectura, escultura, grabado, litografía; las obras fotográficas a las cuales se asimilan las expresadas por procedimiento análogo a la fotografía; las obras de artes aplicadas; las ilustraciones, mapas, planos, croquis y obras plásticas relativos a la geografía, a la topografía, a la arquitectura o a las ciencias”.

El Convenio de París en su artículo primero consagra que

"la protección de la propiedad industrial tiene por objeto las patentes de invención, los modelos de utilidad, los dibujos o modelos industriales, las marcas de fábrica o de comercio, las marcas de servicio, el nombre comercial, las indicaciones de procedencia o denominaciones de origen, así como la represión de la competencia desleal".

La ambigüedad que compone la falta de claridad sobre cuáles son las creaciones que pueden protegerse por medio de las Convenciones de propiedad intelectual, permite el abuso de ciertos sectores; mientras que un lienzo pintado de un solo color montado en un marco es calificado como obra por la Convención de Berna, las creaciones generadas en la industria de la moda no son previstas por dicha normativa (keaton y Goolsby, 2009).

Tanto el Convenio de París como la Convención de Berna consagran un ámbito de aplicación en el que todo país que forme parte se compromete a adoptar, de conformidad con su Constitución, las medidas necesarias para asegurar su aplicación. Es por esto, que nuestra Constitución Nacional consagra en su artículo 61 que el Estado protegerá la propiedad intelectual por el tiempo y mediante las formalidades que establezca la ley.

Más aún, el Tratado de la OMPI sobre derechos de autor, aprobado por la Ley 565 de 2000 consagra en su artículo 2 que la protección del derecho de autor abarcará las expresiones pero no las ideas, procedimientos, métodos de operación o conceptos matemáticos en sí. 
Además de esta normativa internacional, Colombia hace parte de la Comunidad Andina de Naciones, por lo que se aplica el régimen común sobre propiedad intelectual consagrado en la Decisión 351 de 1993, con respecto a los temas de derechos de autor, y la Decisión 486 de 2000 con respecto a los temas de propiedad industrial.

En esta normatividad regional tampoco se aclara el tema de las creaciones generadas en el mundo de la moda, tal como se puede observar en el artículo 4 de la Decisión 351 de 1993, en donde se estipula:

"La protección reconocida por la presente Decisión recae sobre todas las obras literarias, artísticas y científicas que puedan reproducirse o divulgarse por cualquier forma o medio conocido o por conocer, y que incluye, entre otras, las siguientes:

a) Las obras expresadas por escrito, es decir los libros, folletos y cualquier tipo de obra expresada mediante letras, signos o marcas convencionales;

b) Las conferencias, alocuciones, sermones y otras obras de la misma naturaleza;

c) Las composiciones musicales con letra o sin ella;

d) Las obras dramáticas y dramático-musicales;

e) Las obras coreográficas y las pantomimas;

f) Las obras cinematográficas y demás obras audiovisuales expresadas por cualquier procedimiento;

g) Las obras de bellas artes, incluidos los dibujos, pinturas, esculturas, grabados y litografías;

h) Las obras de arquitectura;

i) Las obras fotográficas y las expresadas por procedimiento análogo a la fotografía;

j) Las obras de arte aplicado;

k) Las ilustraciones, mapas, croquis, planos, bosquejos y las obras plásticas relativas a la geografía, la topografía, la arquitectura o las ciencias;

l) Los programas de ordenador; 
II) Las antologías o compilaciones de obras diversas y las bases de datos, que por la selección o disposición de las materias constituyan creaciones personales”.

En la normatividad interna anterior a la Decisión 351 se presenta el mismo vacío con respecto a los mecanismos de protección de las creaciones del mundo de la moda. Tal es así que el artículo segundo de la Ley 23 de 1982 se estipula que

"Los derechos de autor recaen sobre las obras científicas, literarias y artísticas en las cuales se comprenden todas las creaciones del espíritu en el campo científico, literario y artístico, cualquiera que sea el modo o forma de expresión y cualquiera que sea su destinación, tales como: los libros, folletos y otros escritos; las conferencias, alocuciones, sermones y otras obras de la misma naturaleza; las obras dramáticas o dramático-musicales; las obras coreográficas y las pantomimas; las composiciones musicales con letra o sin ella; las obras cinematográficas, a las cuales se asimilan las obras expresadas por procedimiento análogo a la cinematografía, inclusive los videogramas; las obras de dibujo, pintura, arquitectura, escultura, grabado, litografía; las obras fotográficas a las cuales se asimilan las expresadas por procedimiento análogo a la fotografía; las obras de arte aplicadas; las ilustraciones, mapas, planos, croquis y obras plásticas relativas a la geografía, a la topografía, a la arquitectura o a las ciencias, $y$, en fin, toda producción del dominio científico, literario y artístico que pueda reproducirse, o definirse por cualquier forma de impresión o de reproducción, por fonografía, radiotelefonía o cualquier otro medio conocido o por conocer".

Del mismo modo, dentro de las definiciones que trae la Decisión 486 de patentes, modelos de utilidad, esquemas de trazados de circuitos integrados, diseños industriales, marcas, nombres comerciales, indicaciones geográficas y signos distintivos notoriamente conocidos; aparentemente, tampoco tienen cabida las creaciones de la industria de la moda.

\section{Argumentos en pro y en contra de la legislación de moda}

La ausencia de protección en el mundo de la moda viene de tiempo atrás. Algunos actores de la industria han considerado que estas creaciones no pueden protegerse por medio de derechos de autor, pues su finalidad es utilitaria y dicho mecanismo de protección deja por fuera las obras que tengan una finalidad de uso (Barton, 2009); es así, como se estima que al generar mecanismos de protección para estas creaciones podrían surgir monopolios, por ello, fundamentan su negación a la propiedad con la finalidad de promover la igualdad social.

Lo que más preocupa a los doctrinantes es que la protección a este tipo de creaciones aumente los costos de los productos, ello, teniendo en cuenta que de cierto modo se crearía un privilegio en la producción de los bienes protegidos (Clifford, 2011).

Se sostiene por esta corriente que el proceso creativo de hoy es casi totalmente dependiente de las formas de reutilización, y es quizá el mundo de la moda el más cíclico de todos los sectores de diseño (Sinnreich y Gluck, 2005); por tanto, es usual ver en las pasarelas de moda varios diseños similares a los que se usaron tiempo atrás. Evidentemente, los diseñadores reinventan algún elemento, pero en su conjunto son tendencias traídas del pasado. 
Dentro de las características del negocio se encuentra la agilidad en la innovación, si se tiene en cuenta que las tendencias van cambiando de temporada a temporada, es necesario que los creativos de la industria vayan a este ritmo, pues de lo contrario sus diseños podrían ser catalogados como obsoletos (Blakley, 2010). Esta velocidad es marcada por la rapidez del mercado y de la economía, la existencia de un sistema capitalista en el que cada vez las personas adquieren bienes y servicios con mayor celeridad, genera la necesidad de agilizar el cambio.

Algunos doctrinantes se han atrevido incluso a afirmar que la copia en el mundo de la moda es positiva, pues las modificaciones que se hacen en el momento de la copia pueden inspirar a los diseñadores originales en direcciones que no fueron exploradas antes (El Harbi y Grolleau, 2008); por ejemplo, en el uso de materiales más económicos que no habían sido utilizados por ellos.

Adicionalmente, la incursión de las tecnologías de la información en la industria ha generado la posibilidad de copiar, de una manera muy ágil. Mientras una colección es presentada en las pasarelas, inmediatamente podrán ser tomadas las imágenes para ser enviadas a replicar. Es decir, podrían presentarse copias en menos de una semana.

Dentro del negocio de la piratería hay varios participantes, entre ellos, los plagiadores directos, y actores secundarios que ayudan y son cómplices de los falsificadores; dentro de ellos, se encuentran personas que pueden desempeñarse en diversos campos, entre ellos los distribuidores y proveedores, que contribuyen a esta práctica con conocimiento o no (Arden, 2009).

En las cadenas de ventas por internet es común la presencia de productos falsificados, ello, debido a la libertad de venta. Un ejemplo es e-bay, en dónde se han encontrado productos falsificados de las marcas Louis Vuitton y Tiffany's. Frente a estos casos difundidos por la prensa se tomaron decisiones diferentes; mientras que la justicia de Estados Unidos al estudiar el caso Tiffany's consideró que e-bay no estaba infringiendo la marca pues no conocía que el producto era falsificado, la justicia Francesa sostuvo que e-bay había sido negligente pues no había prevenido la violación marcaria (Sigler, 2010).

Algunos pensadores indican que la industria de moda florece porque copiando se popularizan los estilos particulares, y entonces, permite el acceso de toda la sociedad a modelos que si no hubiesen sido copiados no habrían podido ser adquiridos (Dreyguss, 2010). Por esta misma línea, algunos se preguntan si con la protección específica de este tipo de creaciones, se privatizaría de cierta forma algún material o alguna creación específica.

Es importante tener en cuenta que el gobierno de China, país conocido por tener uno de los mercados mundiales más grandes de productos falsificados y plagiados, ha implementado nuevas políticas contra la piratería; sin embargo, muchos comerciantes siguen renuentes a renunciar a este negocio lucrativo. Después de varias demandas interpuestas por grandes marcas, la piratería ha tenido un pequeño retroceso, pero no se ha logrado eliminar por completo (Yahong, 2009). 
A pesar que varios diseñadores de la talla de Tom Ford, han sostenido en diferentes entrevistas que la piratería y plagio no los afecta directamente a ellos, pues los clientes que adquieren sus productos no son los mismos que adquieren productos falsificados (Ford, 2008); este es un tema de suma importancia social; y, por tanto, debe estar presente en los debates que se generen sobre la protección o no de las creaciones generadas en el mundo de la moda. Sobre este particular, es importante tener en cuenta que la copia no sólo se aprovecha de los grandes diseñadores, sino también de los pequeños, quienes se verían altamente afectados.

Por último, para aquellos que definitivamente niegan la protección de las creaciones generadas en el mundo de la moda, los productos que se originan dentro de esta no son más que la repetición de tendencias anteriores, por tanto, carecen de distintividad. Por añadidura, sostienen que proteger este tipo de creaciones es similar a proteger el estilo de cada persona, una receta, un juego, un mueble o un tatuaje y, por tanto, sería un error hacerlo; por ello pregonan un sí a la libre circulación (Blakley, 2010).

Buscando mecanismos de protección, diseñadores textiles, de moda, y en general los creativos del mercado, sostienen que sus productos son diferentes a los demás elaborados en el interior de este mercado, de ahí que deberían tener un amparo específico.

Es así como encontramos la postura contraria, creadores que se resisten frente al no amparo de la ley. De esta manera, es fundamental definir un mecanismo de protección específico para este tipo de creaciones, pues son obras del intelecto humano que deben ser protegidas. Adicionalmente, se debe tener en cuenta que las legislaciones protegen a los consumidores frente al riesgo de confusión, y la no protección de este tipo de creaciones fomentaría este riesgo (Karr, 2003), pues un bien repetido en igualdad de condiciones por otro productor diferente al autorizado, habría cruzado la línea a la falsificación, y por tanto, generaría confusión en el consumidor sobre la procedencia del producto.

Frente al argumento de los opositores sobre la imposibilidad de protección a los artículos útiles, es importante reconocer que dichos bienes merecen protección tengan o no una incorporación de utilidad. Y aunque sean o no útiles, son creaciones del intelecto humano, y tal como lo consagra el artículo 61 de la Constitución Nacional de Colombia, el estado protegerá la propiedad intelectual por el tiempo y mediante las formalidades que establezca la ley.

Mientras que algunos no apoyan la protección por temor a la generación de monopolios, esta corriente afirma que la protección de este tipo de creaciones no generará ningún tipo de distinciones económicas, pues lo que se está forjando es un reconocimiento a los creadores que invierten altas sumas de dinero en el desarrollo de sus creaciones.

Quizá, el gran afectado con la no protección es el diseñador más pequeño, el menos consolidado, el independiente, el que no tiene mayor reconocimiento. A estos diseñadores sería muy sencillo copiarlos, pues no tienen 
ningún tipo de registro y por decirlo de alguna forma, no ocupan una posición representativa en el mercado, que limite a otros para copiarlos (Tan, 2010).

A saber, ellos sostienen que la no protección perjudica también a los fabricantes de prendas de vestir, debido a la poca confianza que les genera invertir en diseño, fabricación y distribución de nuevos productos, sin que se garantice su defensa frente a posibles plagios (Cox, 2005). Es decir, los fabricantes se abstienen de invertir en las creaciones de vestuario para evitar futuras copias, y por tanto, pérdidas económicas. Es así como dan respuesta a la preocupación que existe sobre el aumento de costos de los productos, pues se sostiene que si se genera protección, más personas confluirán al negocio, habrá más competencia, y por ende los precios podrán mantenerse o descender.

La cuestión de la protección legal para el diseño de la moda, presenta un balance óptimo entre, por una parte, proveer un incentivo para crear nuevas obras; y, por otra parte, promocionar los dos objetivos a) hacer las creaciones existentes asequibles a los consumidores y b) hacer que el material esté disponible para el uso subsecuente por parte de nuevos innovadores. A partir de este escenario, es indispensable entender que las tendencias de la moda son una manifestación particularmente vívida de la innovación general, en la que siempre tienen referentes comprometidos con la innovación continua, aunque simultáneamente converjan ideas particulares.

Los diseñadores pueden suministrar artículos de tendencia sin que necesariamente esos productos sean copiados de otros. De hecho pueden participar en la interpretación simplemente haciendo una referencia en su trabajo, a un diseño anterior. A diferencia de la copia cercana, en donde la interpretación no pasa de tomar en cuenta el trabajo, sino de copiar de manera directa el objeto; en la interpretación se puede tener una referencia sobre un trabajo previo, que sirvió como medio de inspiración para un nuevo trabajo. De hecho, si una marca se percata del parecido entre dos trabajos, el nuevo trabajo puede haber hecho una reminiscencia inconsciente e indirecta del nuevo trabajo, siendo una propuesta predecesora, sin ser una copia de este (Raustiala y Sprigman, 2009).

La moda no se construye, solamente, con base en la imitación de las élites o de la adaptación de una moda original anterior, porque su quehacer no se reduce a la copia. Elegir una moda significa definir una expresión de la individualidad que se combinan con los gustos colectivos; la moda refleja el deseo por lo nuevo, por un movimiento de la colectividad, por estar en contacto con el espíritu de la época. Esta teoría nos permite separar las tendencias de la moda, de las simples copias; el movimiento de la moda no es necesariamente el resultado de la saturación del mercado con copias, las copias pueden jugar un papel en el cambio de la moda, pero no son la causa de que la innovación en la moda, se quede detenida y estancada (Hemphill y Suk, 2009).

En el desarrollo de un nuevo modelo, diseñadores pequeños y reconocidos, deben invertir altas sumas de dinero en su producción. Para sacar un bien al mercado es necesario diseñarlo, estudiar los materiales que pueden aprovecharse en su desarrollo, producirlo y por último, ponerlo en el mercado. En esta cadena aparentemente sencilla, es necesario invertir altas sumas de dinero, por lo que es necesario reconocer el ingenio y los costos de desarrollo a los creadores innovadores que sacan productos al mercado (Copyright Office of The United States of America, 2006). 
Frente a la preocupación de paralización del sector por protecciones absolutas, se ha sostenido que al ser un mercado diferente, las legislaciones deberán tener en cuenta su principal característica, el cambio; y por tanto, los tiempos de protección no deberán ser iguales a los otorgados por otros mecanismos previstos por las leyes de propiedad intelectual.

Según los defensores de esta postura, lo más importante -al momento de determinar si un bien puede protegerse o no- es comprobar su distintividad; pero, demostrar esto no es una tarea fácil; por este motivo, la Corte Suprema de Estados Unidos de América ha considerado importante realizar una evaluación, en la que se verifique la distintividad inherente al diseño cuando este sale al mercado, y posteriormente la adquirida cuando el diseño ya lleva un tiempo en el mercado y los consumidores han hecho asociaciones con la marca; ello, con la finalidad de determinar si en realidad aquellos productos que se consideran "diferentes" en realidad lo son (Munsinger, 2000).

Estos autores, aceptan que cada empresa tiene su mercado, por tanto, exista o no protección, siempre será evidente que las personas más adineradas accederán a los productos más costosos, mientras que las otras, accederán a los productos que estén acordes a sus ingresos.

Hablar de protección no es igual a hablar de uniformidad. Mientras algunos opositores inquietos con la protección sustentan que apadrinar este tipo de creaciones es como tutelar el estilo propio, o una receta de cocina, los defensores de la protección insisten en que no puede asimilarse defensa con unicidad en el estilo. Cada persona tiene el derecho a escoger qué prenda de vestir utiliza y qué prenda no.

Para concluir, esta corriente insiste en que es necesario gozar de una legislación específica para la moda, o por lo menos una interpretación uniforme con respecto a los mecanismos de protección que trae la legislación de propiedad intelectual, para de esta forma impedir inconsistencias e incertidumbres jurídicas (Kevin, 2010).

Es evidente que existen dos corrientes marcadas frente a la protección de las creaciones que se generen dentro del mundo de la moda. Una, que implora por una legislación específica de tutela acerca del tema, y otra, que se opone rotundamente a la expedición de este tipo de normatividad. Independientemente a esto, es primordial determinar cómo podrían protegerse este tipo de creaciones, teniendo en cuenta que no existe una legislación exclusiva que regule el tema en Colombia, y que para algunos creadores es imprescindible obtener amparo.

\section{Mecanismos de protección: legislación aplicable a creaciones de moda}

El Convenio de Berna en su artículo 2 estipula cuáles son las obras protegidas por derechos de autor, e incluye en su enumeración ejemplificativa de obras consagrada en el artículo 2.1, a las pinturas o dibujos, esculturas y artes aplicadas, pero tal como lo enseña el artículo 2.7 deja reservada a las leyes nacionales la facultad de regular lo concerniente a las mismas. Igualmente, la Resolución Comunitaria Andina número 351 de 1993, consagra en su artículo 3 la definición de obra, obra de arte aplicado y obra plástica o de bellas artes. 
Tal como lo indica la legislación comunitaria, se entiende por obra toda creación intelectual original de naturaleza artística, científica o literaria, susceptible de ser divulgada o reproducida en cualquier forma. Así mismo, el concepto de obra de arte aplicado se aplica también a la creación artística con funciones utilitarias o incorporada en un artículo útil, ya sea una obra de artesanía o producida en escala industrial; y obra plástica o de bellas artes como la creación artística cuya finalidad apela al sentido estético de la persona que la contempla, como las pinturas, dibujos, grabados y litografías. No quedan comprendidas en la definición, a los efectos de la presente decisión, las fotografías, las obras arquitectónicas y las audiovisuales.

La protección que se concede al autor de estas obras del intelecto humano, se da desde el momento mismo de la creación de la obra sin que para ello requiera formalidad jurídica alguna. De esa manera, de acuerdo a los artículos 1 de la Decisión Andina 351 de 1993, ly 2 de la Ley 23 de 1982, la finalidad del derecho de autor es reconocer una adecuada y efectiva protección a los autores y demás titulares de derechos sobre las obras, que puedan reproducirse o divulgarse por cualquier forma o medio conocido o por conocer, y sin importar el mérito literario o artístico ni su destino (Dirección Nacional Derechos de Autor, 2010).

Dentro de los derechos reconocidos al autor se encuentran los morales, los cuales están fuera del comercio, de ahí que no son objeto de negociación, al mismo tiempo que se consideran perpetuos, inalienables e irrenunciables (Dirección Nacional Derechos de Autor, 2006).

Nuestra legislación reconoce como derechos morales la facultad de revindicar la paternidad de la obra en cualquier momento, el derecho a oponerse a toda deformación, mutilación o modificación que atente contra el decoro de la obra o la reputación del autor; la facultad de conservar la obra inédita o divulgarla; la prerrogativa de modificar la creación, antes o después de su publicación; la facultad de retirar la obra de la circulación o suspender cualquier forma de utilización aunque ella hubiese sido previamente autorizada.

A la par de las facultades morales, el régimen autoral reconoce en favor de los creadores una serie de prerrogativas patrimoniales que se traducen en la facultad exclusiva de realizar, autorizar o prohibir cualquier forma de utilización de su obra.

La Dirección Nacional de Derechos de Autor por medio de Concepto 2005-5951 dispuso que en Colombia se pueda proteger el diseño de artículos de la moda a través de la normativa de derecho de autor. Es así, como indicó que es posible proteger el diseño de un autor y el diseño industrial; y la reproducción tridimensional del diseño bidimensional de un artículo de la moda, pues estos podrán constituir una obra derivada.

Hablar de obra derivada es hablar del resultado de la autorización que concede el autor para transformar o modificar su obra originaria, de tal manera, en la creación de aquella, se tomará como base el aporte intelectual de una obra preexistente (Dirección Nacional Derechos de Autor, 2009). Por ello, en las creaciones de moda podría hablarse de un creador originario que autorizaría a otros para generar nuevas creaciones a partir de la suya. 
Si se toma la definición de obra de arte aplicado, se entiende que esta es una producción de forma de expresión (bidimensional o tridimensional) que incorpora un producto; por tanto, es una expresión visual, pues debe ser percibidle a través del sentido de la vista, esencialmente esta obra debe tener un destino utilitario, es decir, se incorpora a artículos de artesanía o producidos a escala industrial (Antequera, 2009). La importancia radica en el valor artístico y no en su carácter funcional, aunque esto determina que la protección dure la vida del autor más de 25 años.

Los diseños creados en el mundo de la moda podrían protegerse por este mecanismo si se tiene presente que estas creaciones tiene una finalidad de uso, la cuál es servir de vestimenta; sin embargo, esto no es suficiente, la creación debe ser de tal nivel, que su valor artístico permita su registro. No sería suficiente la elaboración de una camisa o una falda, pues lo substancial es el valor artístico agregado a la creación, de tal manera que pueda diferenciarse de otra obra de su mismo género, y permita comprender que se trata de una creación artística, sin perjuicio de que la misma tenga funciones utilitarias, o sea incorporada en un artículo útil tal como lo consagra la Resolución 112 de 2008 de la Dirección Nacional de Derechos de Autor.

En ningún caso puede entenderse que dicho requerimiento implica que se deba separar la naturaleza o valor artístico de la obra de arte aplicado de su función utilitaria o su incorporación en un artículo útil.

De otro lado, de acuerdo con lo establecido en el Glosario de la OMPI, la obra artística u obra de arte "es una creación cuya finalidad es apelar al sentido estético de quien la contempla”, por lo que, dentro de las creaciones de orden artístico se encuentra la pintura, escultura, grabados litografías entre otras (Dirección Nacional Derechos de Autor, 2006).

La Dirección Nacional de Derechos de Autor (2006, p.4) cita a Zapata (1991) quién sostiene que "las obras de arte, como realizaciones de forma, no pueden existir sin elementos materiales que se usan para expresarla, fijarla y exteriorizarla; pero la obra en sí misma es distinta, y en sentido eminentemente jurídico, independiente de dichos elementos". Es indiscutible que para realizar una obra de arte son necesarios varios elementos, pero, el objeto de protección de derechos de autor no puede confundirse con el soporte que la contiene.

Por este motivo si algún diseñador optara por proteger su creación bajo esta modalidad, solamente estará protegiendo la pintura que está soportada en una prenda de vestir, es decir, no se estaría protegiendo el conjunto de la prenda de vestir y su obra impresa, sino solamente la obra que está contenida en la prenda de vestir.

El Convenio de París para la protección de la propiedad industrial en su artículo 1 consagra las creaciones que serán protegidas por medio de propiedad industrial, ellas son: patentes de invención, los modelos de utilidad, los dibujos o modelos industriales, las marcas de fábrica o de comercio, las marcas de servicio, el nombre comercial, las indicaciones de procedencia o denominaciones de origen, así como la represión de la competencia desleal. 
Así mismo, nuestra legislación comunitaria, Decisión 486 de 2000 consagra que serán protegidas las patentes, modelos de utilidad, esquemas de trazados de circuitos integrados, diseños industriales, marcas, nombres comerciales, indicaciones geográficas y signos distintivos notoriamente conocidos.

Al hablar de patente la legislación se refiere a la protección que se genera cuando se desarrolla una composición, un aparato, un dispositivo, un procedimiento o un método nuevo que tiene alguna ventaja en comparación con lo ya conocido y soluciona un problema técnico (Superintendencia Industria y Comercio, 2011a).

El título de propiedad, otorgado al titular del derecho de invención, puede clasificarse en la protección que se otorga a todo nuevo producto o procedimiento que ofrece una nueva manera de hacer algo, o una nueva solución técnica a un problema, llamado patente de invención; o en la protección que se otorga a toda nueva forma, configuración o disposición de elementos, de algún artefacto, herramienta, instrumento, mecanismo u otro objeto o de alguna parte del mismo, que permita un mejor o diferente funcionamiento, utilización o fabricación del objeto que le incorpore o que le proporcione alguna utilidad, ventaja o efecto técnico que antes no tenía, llamado patente de modelo de utilidad.

Dentro de los bienes que no se pueden proteger por medio de una patente encontramos las obras plásticas o aquellas que tienen únicamente carácter estético, por lo que, quedan excluidos inmediatamente los diseños creados en el mundo de la moda. Sin embargo, sí podría pensarse en una patente de modelo de utilidad a una modificación excepcional a los textiles, a los broches, entre otros, de las prendas de vestir, cuándo estos incorporen alguna mejoría, provecho o efecto técnico que antes no tenían.

Seguidamente, la normativa consagra la protección a los diseños industriales, los cuales son toda forma externa o apariencia estética de elementos funcionales o decorativos que sirven de patrón para su producción en la industria, manufactura o artesanía; con características especiales de forma que le dan valor agregado al producto y generan diferenciación y variedad en el mercado (Superintendencia de Industria y Comercio, 20011b). El diseño industrial tiene como finalidad darle un aspecto especial al producto, de manera tal que lo haga agradable a la vista $\mathrm{y}$ más llamativo al consumidor, lo que muy seguramente hará que aumente tanto su demanda como su valor comercial.

El artículo 113 de la Decisión 486 de 2000 indica que se considera diseño industrial la apariencia particular de un producto que resulte de cualquier reunión de líneas o combinación de colores, o de cualquier forma externa bidimensional o tridimensional, línea, contorno, configuración, textura o material, sin que cambie el destino o finalidad de dicho producto. Por ello, es evidente que podrán existir diseños que sólo tengan ancho y largo, como dibujos; o diseños tridimensionales que ocupan un lugar en el espacio pues tienen largo, ancho y profundidad. Dentro de los diseños tridimensionales se encuentran los recipientes, los relojes, las joyas, los electrodomésticos, los aparatos eléctricos, los vehículos, las estructuras arquitectónicas, entre otros.

Es indispensable tener presente que tal como lo consagra el artículo 115 de la Decisión 486, solamente serán registrables los diseños industriales que sean nuevos. Un diseño industrial no es nuevo si antes de la fecha de 
la solicitud o de la fecha de prioridad válidamente invocada, se hubiere hecho accesible al público, en cualquier lugar o momento, mediante su descripción, utilización, comercialización o por cualquier otro medio; adicionalmente, un diseño industrial no es nuevo por el mero hecho que presente diferencias secundarias con respecto a realizaciones anteriores o porque se refiera a otra clase de productos distintos a dichas realizaciones.

Es decir, para obtener un registro de diseño industrial se requiere que el objeto que se busca proteger sea nuevo universalmente, lo que significa que no se haya hecho accesible al público antes de la fecha de presentación o de la prioridad válidamente reivindicada, en cualquier lugar o momento, mediante una descripción, utilización o por cualquier otro medio (Superintendencia de Industria y Comercio, 2003a).

Así pues, si un diseño industrial tiene diferencias secundarias con respecto a otro, se considera que no tiene las suficientes características para considerarlo novedoso; entonces, el hecho de que su finalidad sea diferente a un diseño ya existente, tampoco lo eleva a la categoría de novedad.

A partir de estas consideraciones, se podría registrar una prenda de vestir, siempre y cuando esta sea novedosa y no haya sido conocida universalmente. Algunos ejemplos que se contemplan son las posibles modificaciones que se le hicieren a una camisa, una falda, siempre y cuando nunca se hubiere usado. He aquí el gran problema, pues para poder registrar un diseño generado en el mundo de la moda, este debe ser tan único que no se conozca, y teniendo en cuenta una de las características propias de la industrial, la cual es ser cíclica, quedarían por fuera la mayoría de diseños creados en este mercado.

A continuación, la norma comunitaria en su artículo 134 contempla las marcas. Las cuales son cualquier signo que sea apto para distinguir productos o servicios en el mercado. Podrán registrarse como marcas los signos susceptibles de representación gráfica. "De conformidad con lo anterior, la marca es una de las especies de los signos distintivos que utiliza el empresario para identificar en el mercado sus productos o servicios con el objeto de distinguirlos de sus competidores" (Superintendencia de Industria y Comercio, 2003b).

Las marcas podrán ser palabras o combinación de palabras; las imágenes, figuras, símbolos, gráficos, logotipos, monogramas, retratos, etiquetas, emblemas y escudos; la forma de los productos, sus envases o envolturas; cualquier combinación de los signos o medios indicados.

Es esencial que la marca sea perceptible, es así como todo elemento, signo o indicación que tenga debe ser captado por los sentidos para que, por medio de éstos, la marca penetre en la mente del público, el cual la aprehende y asimila con facilidad. Por esto se afirma que la marca debe tener representación gráfica. Igualmente, se habla de distintividad como elemento esencial, pues esa es la finalidad marcaria, identificar los productos o servicios de un empresario de los de los demás (Tribunal de Justicia de la Comunidad Andina, 1994). 
El artículo 134 de la Decisión 486 consagra que podrán constituir marca entre otros, los siguientes signos:

“a) Las palabras o combinación de palabras; b) Las imágenes, figuras, símbolos, gráficos, logotipos, monogramas, retratos, etiquetas, emblemas y escudos; c) Los sonidos y los olores; d) Las letras y los números; e) Un color delimitado por una forma, o una combinación de colores; f) La forma de los productos, sus envases o envolturas; y g) Cualquier combinación de los signos o medios indicados en los apartados anteriores”.

Sobre la anterior definición, se han establecido entonces las siguientes clases de marcas, a saber:

Marcas denominativas: compuesta por varias letras que constituyen un conjunto pronunciable que tenga o no significado. "En este sentido, estas marcas se constituyen por un signo acústico o fonético formado por varias letras que integran un conjunto o un todo pronunciable, que puede o no poseer significado conceptual" (Tribunal de Justicia de la Comunidad Andina, 2005).

Marcas gráficas o figurativas: son las definidas como un "signo visual porque se dirigen a la vista a fin de evocar un figura que se caracteriza por su configuración o forma externa” (Tribunal de Justicia de la Comunidad Andina, 2005).

Marcas mixtas: están compuestas por un elemento denominativo (una o varias palabras) y un elemento gráfico (una o varias imágenes) existiendo siempre un elemento predominante entre ellos.

Marca tridimensional: es la forma particular o especial de un determinado producto que lo haga distintivo a los demás. A este respecto ha dicho la doctrina que "La protección de este tipo de signos depende, en primer lugar de que no estén constituidos por formas usuales o necesarias, y en segundo término, que la forma de que se trate no cumpla, de manera esencial una función técnica (pentagrama)” (Metke, 2002, p. 68).

Marca sonora o auditiva: "constituida por un sonido o combinación de sonidos suficientemente distintivos y susceptibles de representación gráfica”; y marca olfativa, "constituida por un olor suficientemente distintivo y susceptible de representación gráfica (fórmula química)” (Metke, 2002, p. 68).

Es pertinente señalar que el registro marcario otorga a su titular el derecho de usar el signo en forma exclusiva y excluyente. "El titular del mismo tiene la posibilidad de impedir que otras personas, no autorizadas, utilicen o pretendan el registro de la misma marca o de una confundible para los mismos productos o servicios o para productos o servicios relacionados”(Superintendencia de Industria y Comercio, 2003c, p.2).

La regla general es que el derecho exclusivo que para el titular de una marca le otorga el registro de la misma debe circunscribirse al ámbito territorial en que se aplica la ley marcaria (Tribunal de Justicia de la Comunidad Andina, 1998). En consecuencia, un registro de marca válidamente adquirido en Colombia podrá ser usado como 
fundamento de una oposición en otro país de la Comunidad Andina, siempre y cuando quien pretenda oponerse demuestre el interés real en el mercado y haya presentando el registro de la marca al momento de interponer la oposición (Superintendencia de Industria y Comercio, 2003d).

Actualmente, es muy usual ver en las prendas de vestir la marca estampada en algún lugar, y es precisamente, como una forma de protección que el creador realiza esta estampación. Si el empresario tiene registrada su marca, los terceros no podrán usarla, y por tanto, si terceros empiezan a vender productos con su marca estampada, estarían infringiendo el régimen marcario, y por tanto, el empresario titular de la marca podría iniciar acciones legales contra los terceros infractores.

Por consiguiente, varios diseñadores del mundo de la moda han empezado a proteger sus creaciones. Inicialmente ingenian una marca, la registran, y posteriormente proceden a estamparla o incluirla en algún lugar visible de sus creaciones. Si bien es cierto, no están protegiendo la creación como tal, si tienen la marca registrada, y al estamparla en una prenda están identificando el origen del producto, y por tanto, evitando que terceros usen esa marca.

En las altas esferas de la moda es reiterado el uso de marca en las creaciones generadas (carteras, camisas, pantalones) tal es el caso de Luis Vuitton, Carolina Herrera, Lowe, Christian Dior, Chanel entre muchos más. Hoy día, este es el mecanismo con que la mayoría de diseñadores están protegiendo del abuso, sus creaciones.

\section{Conclusiones}

En síntesis, de acuerdo al repaso que se presentó sobre los posibles mecanismos de protección de las creaciones que se generan en su interior, estas pueden resguardarse por diferentes mecanismos previstos en la normativa de derechos de autor $\mathrm{y}$ de propiedad industrial.

Tal es el caso de las obras de arte aplicado y los diseños industriales. Estas dos creaciones irradian elementos en común. Por un lado, son producciones en las que lo que se protege es la forma y no el contenido; son visuales porque deben ser perceptibles por los sentidos; tienen un destino utilitario, es decir, se incorporan a artículos para ser usados; y ambas tienen carácter artístico. Es decir, una obra de arte aplicado puede ser igualmente un modelo de industrial o viceversa (Antequera, 2009).

De otra parte, las obras de arte aplicado podrían registrarse a su vez como modelos de utilidad, siempre y cuando estas obras de arte aplicado cumplieran con los requisitos para adquirir una patente, es decir, ser una nueva forma, configuración o disposición de elementos de algún artefacto, herramienta, instrumento, mecanismo u otro objeto o de alguna parte del mismo, que permita un mejor o diferente funcionamiento, utilización o fabricación del objeto que le incorpore o que le proporcione alguna utilidad, ventaja o efecto técnico que antes no tenía. Por consiguiente, para el registro de una obra como modelo de utilidad se debe verificar su funcionalidad. 
Hay que añadir que una marca tridimensional puede registrarse como una obra de arte, o viceversa. Nada impide que una obra tridimensional pueda registrarse a su vez como una marca tridimensional que pretenda diferenciar productos o servicios, o que por el contrario una marca pueda registrarse a su vez, por los derechos de autor.

Teniendo en cuenta esto, incluso sería posible registrar una obra de arte aplicado como marca y como diseño industrial, siempre y cuando se cumpla con los requisitos previstos por la ley para cada uno de estos casos.

Para concluir, las creaciones de moda no tienen una legislación concreta que se limite a la protección de los derechos de propiedad intelectual sobre ellas; no obstante, puede aplicarse para su tutela la normativa general de derechos de autor y propiedad industrial. El inconveniente de proteger este tipo de obras o creaciones con la normatividad existente es que esta legislación no cumple con una de las características esenciales del negocio, como es la agilidad; podría ocurrir que mientras se cumple con los trámites previstos para el registro, ya se hubiere cambiado de temporada, y por tanto, la prenda fuera considerada dentro del negocio como obsoleta.

Finalmente, y teniendo en cuenta la normativa que se puede aplicar aplicar y las características esenciales de la industria de la moda, tales como innovación, rapidez y circulación, resultaría indispensable preguntarse si sería eficiente tutelar estas creaciones por medio de estos mecanismos. 


\section{Referencias}

1. Alcaldía de Medellín. (s.f.). Guía de Inversión en el sector textil, confección, diseño y moda. Recuperado el 10 de 10 de 2011, de http://es.scribd.com/doc/37519868/Guia-Moda

2. Anónimo. (s.f.). Todos sobre la moda. Recuperado el 21 de 10 de 2011, de http://www.todosobremoda.com/historia.html

3. Antequera, R. (2009). Estudios de Derecho Industrial y Derecho de Autor. Bogotá: Temis.

4. Arden, A. (Septiembre/ Octubre 2009). Righting the Wrong: Recovering Remedies for Trademark Infringement and Counterfeiting. IP Litigator , 1-8.

5. Australian Fashion Council. (2010). Fashion Rules. A Guide to Intellectual Property for Australian's Clothing and Fashion Design Industry. Australia.

6. Bañuelos, M. C. (21 de 10 de 2011). La influencia de la moda en el cambio social de los valores estéticos y corporales. Madrid: Universidad Carlos III de Madrid.

7. Barton, K. (2009). Back to the Beginning: A Revival of a 1913 Argument for Intellectual Property Protection for Fashion Design. Journal of Corporation Law, Vol 35, Num 2 .

8. Blakely, J. (Abril de 2010). Lessons from fashion's free culture. Recuperado el 25 de 07 de 2011, de http://www.ted.com/talks/johanna_blakley_lessons_from_fashion_s_free_culture.html

9. Clifford, S. (3 de 08 de 2011). Even Marked Up, Luxury Goods Fly Off Shelves. Falta ciudad: The New York Times.

10. Comunidad Andina de Naciones. (17 de 12 de 1993). Decisión 351. Lima, Perú.

11. Comunidad Andina de Naciones. (14 de 09 de 2000). Decisión 486. Lima, Perú.

12. Constitución Nacional Colombia. (Julio de 1991). Bogotá, Colombia.

13. Copyright Office of the United States . (27 de 07 de 2006). The Internet, and Intellectual Property, Committe on the Judiciary 19th Congress, 2nd Session. Protection for the Fashion Design . Estados Unidos.

14. Cox Christine, J. J. (2009). Between the Seams, A Fertile Commons: An Overview of the Relationship Between Fashion and Intellectual Property. Santa Monica:.Ready to Share.

15. Dirección Nacional de Derecho de Autor. (2005). Concepto 2005 - 5951 . Bogotá, Colombia.

16. Dirección Nacional de Derechos de Autor. (2006). Concepto 2006 - 13257. Bogotá, Colombia.

17. Dirección Nacional de Derechos de Autor. (2006). Concepto 2006 - 3151. Bogotá, Colombia. 
18. Dirección Nacional de Derechos de Autor. (2009). Concepto 2009 - 7967. Bogotá, Colombia.

19. Dirección Nacional de Derechos de Autor. (03 de 06 de 2010). Obras Derivadas, Radicación No.2-2010-19707. Bogotá, Colombia.

20. Dirección Nacional de Derechos de Autor. (25 de 04 de 2008). Resolución 112. Bogotá, Colombia.

21. Dreyguss, R. (2010). Does IP Need IP? Accommodating Intellectual Production Outside the Intellectual Property Paradigm. Cardozo Law Review, Vol. 31, No. 5 , pp.10-43.

22. El Harbi Sana, G. G. (2008). Profiting from Being Pirated by "Pirating" the Pirates. KYLOS, Vol 61 ,pp. $385-390$.

23. Ford, T. (13 de 06 de 2008). Ready to Share: The Ecology of Creativity in Fashion .

24. Hemphill Scott, S. J. (2009), . The Law, Culture, and Economics of Fashion, vol.61. Stanford Law Review.

25. Instituto para la explotación y la Moda. (s.f.). Inexmoda. Recuperado el 10 de 10 de 2011, de http://www.inexmoda.org.co/prensa/Comunicadosoficiales/Colombiamoda/2011/ LasemanadelamodadeColombia/tabid/5941/Default.aspx

26. Karr, R. (18 de 09 de 2003). Fashion Industry Copes with Designer Knockoffs With Copyright Protection Elusive, Copies are Common. $n p r$.

27. Keaton Ashlye, G. J. (Fall de 2009). In the Trenches of Copyright Law: Challenges and Remedies. Tulane Journal of Technology \& Intellectual Property .

28. Kevin, T. (2010, Vol 18). Counterfeit Fashion: The Interplay Between, Copyright and Trademark Law in Original Fashion Designs and Designer Knockoffs. Texas Intellectual Property Law Journal .

29. Lannelongue, M.-P. (2008). Los Secretos de la Moda al Descubierto. España: GG Moda.

30. Mackenzie, M. (2010). Ismos para entender la moda. Londres: Turner.

31. Mencken, J. (12 de Diciembre de 1997). Boston College. Recuperado el 18 de Julio de 2010, de A Design for the Copyright of Fashion: http://www.bc.edu/bc_org/avp/law/st_org/iptt/articles/ content/1997121201.html

32. Metke, R. (2002). Lecciones de Propiedad Industrial, Tomo III. Bogotá: Raisbeck, Lara, Rodríguez y Rueda.

33. Munsinger, I. (2000). Trade Dress for SccesI Fashion Designs as Distinctive Product Configurations. Texas Review of Entertainment \& Sports Law . 
34. Organización Mundial de la Propiedad Intelectual. (s.f.). ¿Qué es la Propiedad Intelectual? Recuperado el 08 de 10 de 2011, de http://www.wipo.int/freepublications/es/intproperty/450/ wipo_pub_450.pdf

35. Organización Mundial de la Propiedad Intelectual. (9 de 09 de 1986). Convenio de Berna. Berna, Suiza.

36. Organización Mundial de la Propiedad Intelectual. (20 de 03 de 1883). Convenio de París. París, Francia.

37. Proexport. (s.f.). Invierta en Colombia. Recuperado el 20 de 10 de 2011, de http://www.slideshare.net/inviertaencolombia/sector-textil-y-confecciones-proexport-1187038

38. Raustiala kal, S. C. (2009, Vol 61). Response The Piracy Paradox Revisited. Standford Law Review.

39. Real Academia de la Lengua Española. (2009). Diccionario de la real academia de la lengua española. Madrid: Espasa.

40. Sigler, A. (2010, Vol 14 núm 1). Online auction House Liability for the Sale of Trademark Infringing Productos. Marquette intellectual property law review .

41. Sinnreich Aram, G. M. (2009). Music \& Fashion: The Balancing Act Between Creativity and Control. Ready to Share. Santa Monica: USC Annenberg School of Communication.

42. Superintendencia de Industria y Comercio. (26 de 05 de 2003). Concepto 2116. Bogotá, Colombia.

43. Superintendencia de Industria y Comercio. (16 de 06 de 2003). Concepto 2160. Bogotá, Colombia.

44. Superintendencia de Industria y Comercio. (26 de 10 de 2011). Guia Diseño Industrial. Bogotá, Colombia.

45. Superintendencia de Industria y Comercio. (14 de 04 de 2003). Concepto 2067 No.03007302. Bogotá, Colombia.

46. Superintendencia de Industria y Comercio. (15 de 10 de 2003). Concepto 2202. Bogotá, Colombia.

47. Superintendencia de Industria y Comercio. (26 de 10 de 2011). Guia Patentes y Modelos de Utilidad. Bogotá, Colombia.

48. Tan, I. (2010, Vol 18). Knock it Off, Forever 21! The Fashion Industry's Battle Against Design Piracy. Journal of Law and Policy .

49. Tribunal de Justicia de la Comunidad Andina de Naciones. (1994). Proceso 04-IP-94. Quito, Ecuador. 
50. Tribunal de Justicia de la Comunidad Andina de Naciones. (21 de Abril de 1998). Proceso 17 - IP - 98. Lima, Perú.

51. Tribunal de Justicia de la Comunidad Andina de Naciones. (09 de 03 de 2005). Proceso 17-IP-2005. Lima, Perú.

52. Tu, K. V. (2010, Vol 18). Counterfeit Fashion: The Interplay Between, Copyright and Trademark Law in Original Fashion Designs and Designer Knockoffs. Texas Intellectual Property Law Journal .

53. Tungate, M. (2008). Marcas de moda marcar estilo desde Armani a Zara. España: Gustavo Gili.

54. Vásquez, A. (2007). La moda en la postmodernidad deconstrucción del fenómeno fashion. Revista electrónica DU\&P. Diseño Urbano y Paisaje VOlumen IV No. 11 , 1-10.

55. Yahong, L. (s.f.). China Today. Recuperado el 10 de 08 de 2011, de http://www.chinatoday. com.cn/ctenglish/se/txt/2009-03/10/content_184191.htm 